\title{
Associations between occupational inhalation risks and FeNO levels in airway obstruction patients: results from the National Health and Nutrition Examination Survey, 2007-20I2
}

\author{
This article was published in the following Dove Press journal: \\ International Journal of COPD \\ 20 October 2017 \\ Number of times this article has been viewed
}

\author{
Yi-Chih Huang ${ }^{1,2}$ \\ Mei-Chen Yang ${ }^{1,2}$ \\ 'Division of Pulmonary Medicine, \\ Department of Internal Medicine, \\ Taipei Tzu Chi Hospital, Buddhist Tzu \\ Chi Medical Foundation, New Taipei \\ City, ${ }^{2}$ The School of Medicine, Tzu-Chi \\ University, Hualien, Taiwan
}

Purpose: To investigate associations between occupational inhalation risks and fractional exhaled nitric oxide (FeNO) levels in patients with chronic obstructive pulmonary disease (COPD).

Patients and methods: Data of 16,486 subjects who had undergone spirometry with prebronchodilator and post-bronchodilator lung function assessment were retrieved from the National Health and Nutrition Examination Survey, 2007-2012 database. After excluding 2,638 subjects with missing spirometry values, data of 13,336 subjects were included for analysis. Factors associated with occupational inhalation, FeNO levels and COPD were analyzed using logistic regression analysis.

Results: COPD was associated with occupational exposures to mineral dusts, organic dusts, exhaust fumes, other fumes, and second-hand smoking $(P<0.05)$. Long-term exposure to these occupational hazards carried significantly higher risk for subjects with COPD than for controls (crude odds ratios [ORs]: mineral dusts: 2.364, organic dusts: 2.427 , exhaust fumes: 2.728 , other fumes: 2.144 ). In subgroup analysis, COPD correlated positively with long-term exposures to organic dusts and exhaust fumes in subjects with FeNO $\leq 50 \mathrm{ppb}$ (ORs 1.361 and 1.314 , respectively); conversely, COPD correlated negatively with intermediate to long-term exposures to organic dusts and exhaust fumes in those with FeNO $>50 \mathrm{ppb}$ (ORs 0.058 and 0.210 , respectively).

Conclusion: Occupational exposures to airborne pollutants carries higher risk of COPD than non-exposure and the risk is higher the longer the duration of exposure. Exposure-response relationships are inconsistent in subjects with suspected asthmatic airway inflammation (FeNO $\geq 50 \mathrm{ppb}$ ). More careful risk assessment is needed in occupational inhalation exposure, since COPD with asthmatic airway inflammation, or asthma-COPD overlapping syndrome, may have the distinguishing features of both COPD and asthma.

Keywords: chronic obstructive pulmonary disease, COPD, fractional exhaled nitric oxide, FeNO, occupational inhalation risk

\section{Introduction}

Chronic obstructive pulmonary disease (COPD), a group of lung diseases that includes chronic bronchitis and emphysema, refractory asthma and forms of bronchiectasis, is characterized by prolonged airflow obstruction that is typically associated with an aggravated chronic inflammatory response in the airways. ${ }^{1}$ The increased breathlessness and overall severity of COPD in individual patients is influenced by 
the effects of various exacerbating factors and comorbidities such as lung cancer, cardiovascular disease, diabetes and others. $^{2,3}$ Most COPD patients have other systemic manifestations, making it a complex chronic systemic disease. ${ }^{4}$ About $15 \%-20 \%$ of asthma patients also have airflow limitations associated with COPD, a condition referred to as asthma-COPD overlapping syndrome (ACOS), and although ACOS is a separate disease entity, it may exhibit the distinguishing features of both COPD and asthma. ${ }^{3}$ Asthma and COPD may actually be on opposite ends of the spectrum of chronic obstructive airway diseases, making diagnosis even more complex. ${ }^{5}$

COPD is a leading cause of morbidity and mortality among adults in the United States, with a prevalence of $3.2 \%$ in adults aged 18-44 years, increasing to $11.6 \%$ in those aged 65 years and older; it affects more than $5 \%$ of the population (about 30 million individuals) and more than 120,000 individuals die of the disease annually. ${ }^{6}$ Although cigarette smoking is the foremost risk factor for COPD, $50 \%$ of obstructive lung diseases are attributed to non-smoking risk factors. ${ }^{7}$ Occupational exposure to inhaled dusts and fumes common in various industries (eg, coal mining, gold mining and cotton textiles), environmental exposure and household sprays and mists are also known risk factors for COPD. ${ }^{8,9}$ However, while evidence of the effects of occupational exposure to a wide variety of workplace pollutants on COPD development continues to grow, ${ }^{9}$ differences in risk have not been found in common forms of environmental or occupational exposure such as vapors, gases, dusts and fumes (VGDF) or fibers and mists. ${ }^{8}$ A recent review study of occupational influences on lung disease emphasizes that the clinical features of occupationally induced COPD cannot be distinguished from the same disease attributed to other causes. ${ }^{10}$ This fact makes health surveillance in the workplace especially difficult, requiring that lung function measurement in COPD surveillance must consider misattribution of lung function changes to non-workplace exposures.

Defining the presence and severity of airway obstruction in COPD relies on pulmonary function testing, including post-bronchodilator spirometry testing that measures the ratio of forced expiratory volume in 1 second $\left(\mathrm{FEV}_{1}\right)$ to forced vital capacity (FVC), with results below 0.7 suggesting airway obstruction. ${ }^{11}$ Fractional exhaled nitric oxide (FeNO) is a biomarker for COPD and related comorbidities. ${ }^{3}$ As a good indicator of eosinophilic airway inflammation, FeNO is used to diagnose steroid-responsive disease and to guide the routine management of asthma and obstructive lung disease. ${ }^{12}$ Current clinical applications of FeNO include monitoring improvement in spirometry results and airway hyper-responsiveness and easier detection of eosinophilic airway inflammation. ${ }^{13}$ Individuals with high FeNO levels ( $>50 \mathrm{ppb}$ ) may have ACOS but not COPD; patients with ACOS may have certain clinical features of COPD and would therefore be classified as COPD. However, these possible variations in obstructive lung disease have not been examined in conjunction with occupational inhalation risks. Also, although evidence has shown a causal relationship between occupational exposures and COPD development, ${ }^{14}$ the harm of occupational exposure has not been explored systematically using comprehensive patient data such as that available in the National Health and Nutrition Examination Survey (NHANES) database. Therefore, the purpose of this study was to investigate associations between occupational inhalation risks and FeNO levels in COPD patients.

\section{Methods \\ Data source}

Data for the present study were retrieved from three cycles of NHANES spanning 2007-2012. All data were obtained from the Public Data General Release file documents, Centers for Disease Control and Prevention, National Center for Health Statistics (NCHS) and US Department of Health and Human Services. ${ }^{15}$ NHANES data are released for research purposes and permission to use the data is granted to researchers by the NCHS. NHANES includes a stratified, multi-stage probability sample that is representative of the civilian non-institutionalized US population. The NCHS designed NHANES and collected the data after receiving informed consent from either the participants or their parents. All NHANES data are de-identified, and analysis of the data in the present study did not require institutional review board approval or informed consent.

\section{Study population}

This study analyzed the data of subjects aged 20-79 years who underwent spirometry testing while participating in three NHANES data cycles spanning 2007-2012. Among 16,486 subjects eligible for the survey, 15,974 participants who were evaluated at the NHANES Mobile Examination Center (MEC) were invited to undergo spirometry testing, including pre-bronchodilator and post-bronchodilator lung function assessment. For the present study, 2,638 of the 15,974 subjects were excluded because of missing pre-bronchodilator spirometry values. Finally, the data of 13,336 subjects who had received spirometry were included for analysis (Figure 1). Using the NHANES MEC weight, the analytic 


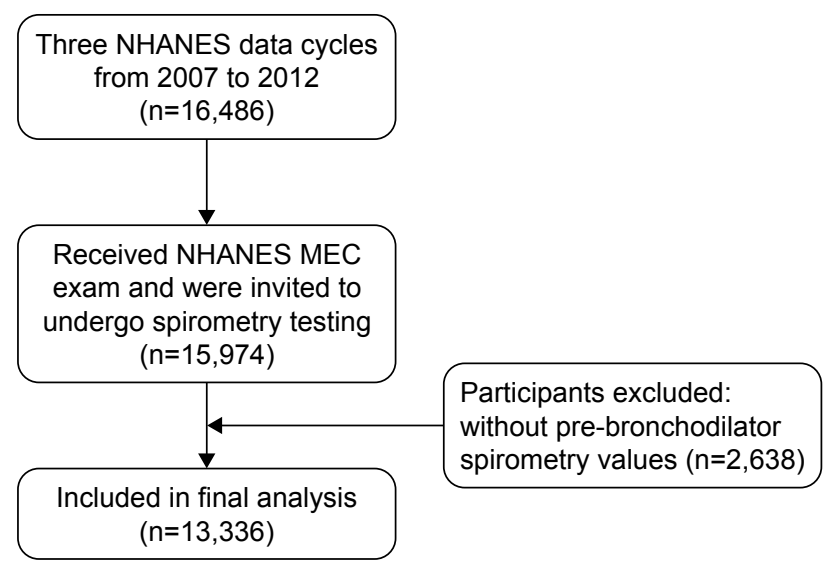

Figure I Flow diagram of selection process.

Abbreviations: MEC, Mobile Examination Center; NHANES, National Health and Nutrition Examination Survey.

sample size $(n=13,336)$ was equivalent to a population-based sample size of $179,998,708$ subjects.

\section{Study variables Demographics}

Age, gender, race/ethnicity and marital status were recorded using the Family and Sample Person Demographics questionnaires, which were administered in home visits by trained interviewers using the Computer-Assisted Personal Interview (CAPI) system (Confirmit Corporation, New York, NY, USA), with demographic variables and sample weights from the NHANES database. Males and females were divided into two separate categories to obtain the different unique risk factors associated with each gender. Race/ethnicity was self-reported as Mexican American, other Hispanic, non-Hispanic White, non-Hispanic Black and other race including multiracial. Education level and ratio of family income to poverty were also recorded using the interviewer-administered questionnaires with demographic variables and sample weights from the NHANES database. Family income/poverty ratio was defined as the ratio of family income to the poverty threshold, with a range of values from 0 to 5 , and values of 5 and greater recorded as 5 . Income levels were stratified into four levels according to the federal poverty level (FPL): 0\%-50\%, 51\%-100\%, 101\%-130\% and $>130 \%$. Respondents' education levels were categorized as under high school, high school level and college level or above.

\section{Occupational inhalation risks}

The Occupation Questionnaire Section of the NHANES database (prefix OCQ; questions OCD150-OCQ580) contains Sample Participant interview data on employment and variables related to the work environment, including lifetime history of exposure to mineral and organic dusts and fumes, for respondents aged 16-79 years. To quantify the accumulated risk for each respondent, the years of exposure were classified into four groups: non-exposure (within 1 year), short-term (1-3 years), intermediate (4-10 years) and longterm exposure $(>10$ years).

\section{Smoking}

The dataset for Smoking Cigarettes (variable name prefix SMQ) provides data on lifetime cigarette use (ie, history of use, age at initiation, current use, number of cigarettes smoked in past 30 days, etc.). Smoking history was quantified in pack-years. Smoking volume for current smokers was calculated by duration of smoking multiplied by average numbers of cigarettes smoked at time of survey. Smoking volume for previous smokers (quitters) was quantified by duration of smoking (age at quitting smoking minus age at which smoking started) multiplied by average numbers of cigarettes smoked in respondent's entire smoking history.

\section{Airway obstruction}

Spirometry or pulmonary function tests were conducted by NHANES to determine prevalence of asthma or COPD and to update spirometric reference data for the US population. Examinees with current chest pain; physically incapable of forced expiration; receiving supplemental oxygen; recent eye, chest or abdominal surgery; personal history of heart attack, stroke or tuberculosis; or recently coughed up blood were excluded. Adults with a personal history of detached retina or collapsed lung were also excluded. Results of baseline (pre-bronchodilator) spirometry tests of $\mathrm{FEV}_{1}$ and $\mathrm{FVC}$ were used to gauge degree of possible airway obstruction $\left(\mathrm{FEV}_{1} / \mathrm{FVC}<70 \%\right)$ and to define COPD.

\section{$\mathrm{FeNO}$}

Baseline FeNO measurements were used to define reference ranges for the US healthy population, asthma and COPD patients, and smokers, as well as undiagnosed airway inflammation. Subjects with current chest pain, problems with forced expiration or using supplemental oxygen were medically excluded. FeNO levels were measured using the Aerocrine $\mathrm{NIOX} \mathrm{MINO}^{\circledR}$, a portable, hand-held NO analyzer (Aerocrine AB, Solna, Sweden) with an electrochemical sensor to detect exhaled NO levels, providing measurements of FeNO from 5 ppb to $300 \mathrm{ppb}$ in whole numbers. The tests were conducted according to the NHANES Laboratory Protocol. ${ }^{16}$ Subjects underwent up to 10 consecutive tests for valid measurements. Subjects with FeNO levels $>50 \mathrm{ppb}$ 
were defined as having eosinophilic (asthmatic) airway inflammation. The cutoff point was used to further stratify COPD patients with different occupational exposures.

\section{Statistical analysis}

Differences in categorical variables between patients with and without COPD were determined using Rao-Scott chisquare test, and differences in continuous variables between groups were examined using the Complex Samples General Linear Model. Demographic data and baseline clinical characteristics were expressed as mean \pm standard error for continuous variables, and unweighted counts (weighted \%) for categorical variables. Univariate and multivariate logistic regression analyses were performed to determine associations between occupational exposure (eg, mineral dusts, organic dusts, exhaust fumes, other fumes and second-hand exposure) and the risk of COPD. Two multivariate models were utilized to analyze adjusted odds ratios (ORs). In the first model, variables to adjust included demographic factors (age, gender, race, education, marriage, smoking and ratio of family to the FPL). In the second model, levels of FeNO were also included into the adjustment. To address oversampling, non-response, non-coverage and to provide nationally representative estimates, all analyses included MEC exam weight (WTINT2YR), stratum and primary sampling units per NCHS recommendations. All statistical assessments were two-sided and were evaluated at the 0.05 level of significance. Statistical analyses were performed using the statistical software package SPSS complex sample module version 22.0 (IBM Corp, Armonk, NY, USA).

\section{Results}

The study population included 6,681 women (50.5\%) and 6,655 men $(49.5 \%)$ with a mean age of $44.93 \pm 0.36$ years. Prevalence of COPD was $13.6 \%$ based on pre-bronchodilator results, which was equivalent to a population-based sample of $24,426,825$ subjects.

Demographic characteristics and occupational exposure of eligible subjects with and without COPD are summarized in Table 1. Significant differences were found in age, gender, race, education, marital status, FPL and smoking between the two groups $(P<0.05)$. In addition, exposure to mineral dusts, organic dusts, exhaust fumes, other fumes and secondhand smoke exposure were significantly associated with prevalence of COPD $(P<0.05$, Table 1$)$.

Univariate logistic regression revealed that subjects with long-term occupational exposure to mineral dusts, organic dusts, exhaust fumes and other fumes had significantly higher
Table I Demographic characteristics and occupational exposure of subjects with and without COPD

\begin{tabular}{|c|c|c|c|}
\hline Demographics & $\begin{array}{l}\text { With COPD } \\
(n=1,766)\end{array}$ & $\begin{array}{l}\text { Without COPD } \\
(n=11,570)\end{array}$ & $P$-value \\
\hline Age (years) & $56.12(0.49)$ & $43.17(0.34)$ & $<0.00 I^{*}$ \\
\hline Smoking (pack-years) & $18.78(0.95)$ & $5.28(0.27)$ & $<0.00 I^{*}$ \\
\hline \multicolumn{3}{|l|}{ Gender, n (\%) } & $<0.00 I^{*}$ \\
\hline Male & I, 129 (61.1\%) & $5,526(47.6 \%)$ & \\
\hline Female & $637(38.9 \%)$ & $6,044(52.4 \%)$ & \\
\hline \multicolumn{3}{|l|}{ Race, n (\%) } & $<0.00 I^{*}$ \\
\hline Mexican American & $|3|(2.7 \%)$ & I,979 (9.3\%) & \\
\hline Other Hispanic & $12 \mid(2.4 \%)$ & $1,315(6.1 \%)$ & \\
\hline White & I,062 (82.3\%) & 4,637 (65.7\%) & \\
\hline Black & 352 (8.0\%) & 2,562 (1I.8\%) & \\
\hline Other race & 100 (4.6\%) & I,077 (7.2\%) & \\
\hline \multicolumn{3}{|l|}{ Education, n (\%) } & $0.002 *$ \\
\hline Under high school & $518(18.9 \%)$ & $2,877(16.6 \%)$ & \\
\hline High school level & $454(25.5 \%)$ & $2,584(21.8 \%)$ & \\
\hline College level or above & 794 (55.6\%) & 6,109 (61.6\%) & \\
\hline \multicolumn{3}{|l|}{ Marriage, n (\%) } & $<0.00 I^{*}$ \\
\hline Married & I, 128 (70.6\%) & 6,895 (63.0\%) & \\
\hline Widowed & 173 (7.0\%) & $505(2.8 \%)$ & \\
\hline Divorced/separated & $309(14.3 \%)$ & I,637 (I2.6\%) & \\
\hline Never married & 155 (8.1\%) & $2,524(21.6 \%)$ & \\
\hline \multicolumn{3}{|l|}{ FPL, n (\%) } & $0.033^{*}$ \\
\hline QI: $0 \%-50 \%$ & 95 (3.4\%) & 785 (5.1\%) & \\
\hline Q2: $51 \%-100 \%$ & 254 (8.9\%) & I,546 (I0.0\%) & \\
\hline Q3: $101 \%-130 \%$ & 193 (7.0\%) & I,045 (6.4\%) & \\
\hline Q4: $>130 \%$ & I,090 (80.7\%) & 7,201 (78.5\%) & \\
\hline \multicolumn{3}{|c|}{ Mineral dusts exposure, $\mathrm{n}(\%)$} & $<0.00 I^{*}$ \\
\hline Non-exposure & $1,067(63.6 \%)$ & $8,003(72.6 \%)$ & \\
\hline Short-term & $130(7.0 \%)$ & $962(8.9 \%)$ & \\
\hline Intermediate & $170(9.6 \%)$ & $1,049(8.9 \%)$ & \\
\hline Long-term & $360(19.9 \%)$ & $1,102(9.6 \%)$ & \\
\hline \multicolumn{3}{|c|}{ Organic dusts exposure, $\mathrm{n}(\%)$} & $<0.00 I^{*}$ \\
\hline Non-exposure & I,289 (73.8\%) & $8,942(79.9 \%)$ & \\
\hline Short-term & 87 (4.9\%) & $750(7.2 \%)$ & \\
\hline Intermediate & $128(7.6 \%)$ & 748 (6.8\%) & \\
\hline Long-term & $234(13.7 \%)$ & $693(6.1 \%)$ & \\
\hline \multicolumn{3}{|c|}{ Exhaust fumes exposure, $n(\%)$} & $<0.00 I^{*}$ \\
\hline Non-exposure & $1,162(66.7 \%)$ & $8,669(77.5 \%)$ & \\
\hline Short-term & $1 \mathrm{II}(6.6 \%)$ & $738(7.0 \%)$ & \\
\hline Intermediate & 150 (8.7\%) & $858(7.8 \%)$ & \\
\hline Long-term & $316(18.1 \%)$ & $874(7.7 \%)$ & \\
\hline \multicolumn{3}{|c|}{ Other fumes exposure, $\mathrm{n}(\%)$} & $0.001 *$ \\
\hline Non-exposure & $1,095(63.6 \%)$ & 7,978 (7I.7\%) & \\
\hline Short-term & 142 (8.3\%) & $\mathrm{I}, 04 \mathrm{I}(9.8 \%)$ & \\
\hline Intermediate & $179(10.3 \%)$ & $1,063(9.2 \%)$ & \\
\hline Long-term & $322(17.7 \%)$ & $1,056(9.3 \%)$ & \\
\hline \multicolumn{3}{|c|}{ Second-hand smoke exposure, $\mathrm{n}(\%)$} & $0.032 *$ \\
\hline No & $660(83.1 \%)$ & $6,166(86.1 \%)$ & \\
\hline Yes & $142(16.9 \%)$ & I,062 (I3.9\%) & \\
\hline
\end{tabular}

Notes: Data are weighted according to the National Health and Nutrition Examination Survey protocol (unweighted $n=13,336$, weighted $N=179,998,708$ ). Values are expressed as mean (SEs) for continuous variables and unweighted counts (weighted \%) for categorical variables. *Significant difference between the two groups, $P<0.05$.

Abbreviations: COPD, chronic obstructive pulmonary disease; FPL, federal poverty level; SE, standard error. 
odds of having COPD compared to the non-exposure group (crude ORs: mineral dusts: 2.364, organic dusts: 2.427, exhaust fumes: 2.728 , other fumes: 2.144). In addition, subjects with second-hand smoke exposure had 1.259 times greater risk of having COPD compared to those without second-hand smoke exposure (crude OR $=1.259,95 \%$ CI $=1.021-1.552$ ) (Table 2). After adjusting for demographic factors (model 1), both intermediate and long-term exposure to organic dusts and exhaust fumes remained strongly correlated with COPD prevalence (Table 2). After controlling for potential confounders and FeNO levels, subjects with long-term exposure to organic dusts and exhaust fumes had higher odds of having COPD than the non-exposure group (ORs $=1.298$ and 1.270, respectively, model 2, Table 2); however, ORs were less prominent than those seen in model 1 (ORs $=1.350$ and 1.342, respectively).

To explore the possible involvement of asthmatic airway inflammation in each occupational inhalation exposure group, subjects were further stratified into two groups by FeNO levels: Group 1, FeNO $\leq 50$ ppb (without asthmatic airway inflammation), and Group 2, FeNO $>50$ ppb (suggesting asthmatic airway inflammation). Group 1 subjects (FeNO $\leq 50 \mathrm{ppb}$ ) with long-term exposure to organic dusts and exhaust fumes exhibited higher odds of having COPD than their non-exposed counterparts $(\mathrm{OR}=1.361$ and 1.314, respectively, Table 3 ). Group 2 subjects (FeNO $>50 \mathrm{ppb}$ ) with long-term exposure to organic dusts and exhaust fumes displayed substantially lower odds of having COPD than the corresponding non-exposure groups ( $\mathrm{OR}=0.058$ and 0.210 , respectively, Table 3 ). In addition, for participants with normal FeNO levels (Group 1), those who encountered second-hand smoking in their workplace carried a higher risk of COPD than those without exposure (OR=1.318, Table 3 ). In contrast, the higher odds were not observed in Group 2 subjects, who had higher FeNO values.

To further investigate how different inhalation exposures correlate with FeNO $>50$ ppb in COPD patients, we calculated relative odds of short-term, intermediate and long-term exposure compared to their non-exposure counterparts. We found that long-term exposure of mineral dusts, organic dusts and exhaust fumes had lower odds of having FeNO $>50 \mathrm{ppb}$ compared to the corresponding non-exposure group $(\mathrm{OR}=0.315,0.115$ and 0.168 , respectively) (Table 4). Intermediate exposure to other fumes also carried a lower odds of having FeNO $>50 \mathrm{ppb}(\mathrm{OR}=0.178)$. In contrast, short-term exposure to mineral dusts and organic dusts and

Table 2 Logistic regression analysis of factors associated with occupational exposure and COPD

\begin{tabular}{|c|c|c|c|}
\hline $\begin{array}{l}\text { Occupational } \\
\text { exposure }\end{array}$ & Crude OR $(95 \% \mathrm{Cl})$ & $\begin{array}{l}\text { Model I: adjusted } \\
\text { OR }(95 \% \mathrm{Cl})^{\mathrm{a}}\end{array}$ & $\begin{array}{l}\text { Model 2: adjusted } \\
\text { OR }(95 \% \mathrm{Cl})^{\mathrm{b}}\end{array}$ \\
\hline \multicolumn{4}{|c|}{ Mineral dusts exposure } \\
\hline Non-exposure & Reference & Reference & Reference \\
\hline Short-term & $0.896(0.689,1.166)$ & $1.001(0.743,1.349)$ & $0.970(0.700,1.344)$ \\
\hline Intermediate & $1.228(0.937,1.611)$ & $1.256(0.922,1.71 \mathrm{I})$ & $1.237(0.945,1.618)$ \\
\hline Long-term & $2.364(1.950,2.865)$ & I. $179(0.932,1.492)$ & I.I $120(0.892,1.406)$ \\
\hline \multicolumn{4}{|c|}{ Organic dusts exposure } \\
\hline Non-exposure & Reference & Reference & Reference \\
\hline Short-term & $0.746(0.579,0.960)$ & $0.998(0.737,1.350)$ & $0.979(0.695$, I. .379$)$ \\
\hline Intermediate & $1.215(0.956,1.545)$ & $1.314(1.021,1.692)$ & $1.366(1.036,1.801)$ \\
\hline Long-term & $2.427(2.006,2.937)$ & $1.350(1.045,1.744)$ & $1.298(1.002,1.68 I)$ \\
\hline \multicolumn{4}{|c|}{ Exhaust fumes exposure } \\
\hline Non-exposure & Reference & Reference & Reference \\
\hline Short-term & I.084 (0.853, I.379) & $1.211(0.915,1.604)$ & I.244 (0.907, I.706) \\
\hline Intermediate & $1.294(1.027,1.631)$ & $1.306(1.000,1.706)$ & $1.223(0.903,1.657)$ \\
\hline Long-term & $2.728(2.30 \mathrm{I}, 3.233)$ & $1.342(1.085,1.660)$ & $1.270(1.034,1.561)$ \\
\hline \multicolumn{4}{|c|}{ Other fumes exposure } \\
\hline Non-exposure & Reference & Reference & Reference \\
\hline Short-term & $0.956(0.73 \mathrm{I}, \mathrm{I} .25 \mathrm{I})$ & $1.030(0.755,1.406)$ & $0.951(0.672,1.346)$ \\
\hline Intermediate & $1.267(0.972,1.650)$ & 1.279 (0.95।, I.7I9) & I.I $33(0.830,1.545)$ \\
\hline Long-term & $2.144(1.752,2.623)$ & $1.053(0.840,1.32 \mathrm{I})$ & $0.977(0.765,1.247)$ \\
\hline \multicolumn{4}{|c|}{ Second-hand smoke } \\
\hline No & Reference & Reference & Reference \\
\hline Yes & $1.259(1.021,1.552)$ & I.23। (0.97।, I.560) & $1.216(0.978,1.512)$ \\
\hline
\end{tabular}

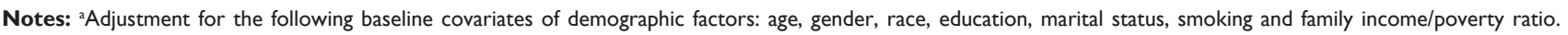
${ }^{b}$ Adjustment for covariates in the first model + FeNO. Significant values are shown in bold $(P<0.05)$.

Abbreviations: COPD, chronic obstructive pulmonary disease; OR, odds ratio; $\mathrm{Cl}$, confidence interval; FeNO, fractional exhaled nitric oxide. 
Table 3 Associations between occupational exposure and COPD by FeNO levels (cutoff point: $50 \mathrm{ppb})^{\mathrm{a}}$

\begin{tabular}{|c|c|c|}
\hline $\begin{array}{l}\text { Occupational } \\
\text { exposure }\end{array}$ & $\begin{array}{l}\text { Group I, } \\
\text { FeNO } \leq 50 \mathrm{ppb} \\
(\mathrm{n}=\mathrm{I}, \mathbf{6 8 7})\end{array}$ & $\begin{array}{l}\text { Group } 2 \text {, } \\
\text { FeNO }>50 \mathrm{ppb} \\
(\mathrm{n}=372)\end{array}$ \\
\hline \multicolumn{3}{|l|}{ Mineral dusts } \\
\hline Non-exposure & Reference & Reference \\
\hline Short-term & $0.940(0.672$, I.3। 5$)$ & $1.580(0.431,5.794)$ \\
\hline Intermediate & $1.300(0.981,1.722)$ & $0.337(0.108,1.054)$ \\
\hline Long-term & I.I $63(0.928,1.456)$ & $0.242(0.058,1.010)$ \\
\hline \multicolumn{3}{|l|}{ Organic dusts } \\
\hline Non-exposure & Reference & Reference \\
\hline Short-term & $0.964(0.67 \mathrm{I}, \mathrm{I} .386)$ & I.222 (0.390, 3.827) \\
\hline Intermediate & $1.396(1.045,1.863)$ & $0.574(0.165,1.999)$ \\
\hline Long-term & $1.361(1.046,1.77 I)$ & $0.058(0.010,0.350)$ \\
\hline \multicolumn{3}{|l|}{ Exhaust fumes } \\
\hline Non-exposure & Reference & Reference \\
\hline Short-term & I.257 (0.904, I.746) & $1.339(0.334,5.370)$ \\
\hline Intermediate & $1.238(0.895,1.712)$ & $\mathrm{I} .073(0.305,3.774)$ \\
\hline Long-term & $1.314(1.061,1.629)$ & $0.210(0.058,0.757)$ \\
\hline \multicolumn{3}{|l|}{ Other fumes } \\
\hline Non-exposure & Reference & Reference \\
\hline Short-term & $0.962(0.683,1.356)$ & $0.749(0.196,2.857)$ \\
\hline Intermediate & $1.181(0.862,1.619)$ & $0.193(0.035,1.065)$ \\
\hline Long-term & I.005 $(0.789,1.280)$ & $0.574(0.138,2.393)$ \\
\hline \multicolumn{3}{|c|}{ Second-hand smoke } \\
\hline No & Reference & Reference \\
\hline Yes & $1.318(1.054,1.649)$ & $0.389(0.141,1.072)$ \\
\hline
\end{tabular}

Notes: adjustment for the following baseline covariates: age, gender, race, education, marital status, smoking and family income/poverty ratio. Significant values in bold $(P<0.05)$.

Abbreviations: COPD, chronic obstructive pulmonary disease; FeNO, fractional exhaled nitric oxide.

Table 4 Associations between FeNO $>50$ ppb and occupational exposure in respondents with COPD

\begin{tabular}{|c|c|}
\hline Occupational exposure & OR $(95 \% \mathrm{Cl})$ \\
\hline \multicolumn{2}{|l|}{ Mineral dusts exposure } \\
\hline Non-exposure & Reference \\
\hline Short-term & $1.724(0.670,4.438)$ \\
\hline Intermediate & $0.770(0.290,2.040)$ \\
\hline Long-term & $0.315(0.131,0.760)$ \\
\hline \multicolumn{2}{|l|}{ Organic dusts } \\
\hline Non-exposure & Reference \\
\hline Short-term & I.238 (0.43।, 3.555$)$ \\
\hline Intermediate & $0.452(0.159,1.290)$ \\
\hline Long-term & $0.115(0.034,0.395)$ \\
\hline \multicolumn{2}{|l|}{ Exhaust fumes } \\
\hline Non-exposure & Reference \\
\hline Short-term & $0.685(0.220,2.132)$ \\
\hline Intermediate & $1.377(0.390,4.854)$ \\
\hline Long-term & $0.168(0.058,0.489)$ \\
\hline \multicolumn{2}{|l|}{ Other fumes } \\
\hline Non-exposure & Reference \\
\hline Short-term & $\mathrm{I} .067(0.400,2.84 \mathrm{I})$ \\
\hline Intermediate & $0.178(0.035,0.901)$ \\
\hline Long-term & $0.573(0.165,1.985)$ \\
\hline
\end{tabular}

Note: Significant values are shown in bold $(P<0.05)$.

Abbreviations: FeNO, fractional exhaled nitric oxide; COPD, chronic obstructive pulmonary disease; $\mathrm{OR}$, odds ratio; $\mathrm{Cl}$, confidence interval. intermediate exposure to exhaust fumes exhibited higher odds of FeNO $>50 \mathrm{ppb}$ compared to the non-exposure group ( $\mathrm{OR}=1.724,1.238,1.377$, respectively), but without statistical significance.

\section{Discussion}

This study investigated associations between occupational inhalation risks and FeNO levels in COPD patients using data from NHANES 2007-2012. The results showed that all occupational exposures of interest were significantly associated with COPD, especially long-term exposure to organic dusts and exhaust fumes. COPD risk was greater with longer exposure to airborne pollutants. Multivariate logistic regression analysis with adjustments for covariates still showed significant risk for the presence of obstructive lung disease in those with intermediate to long-term exposure to organic dusts and exhaust fumes. After stratifying all included subjects by FeNO levels, we found that the impact of inhalation of dusts and fumes remained robust in participants with lower FeNO levels. However, the trend was reversed in subjects with suspected asthmatic airway inflammation (FeNO >50 ppb) - these subjects were less likely to have COPD as the exposed duration increased. In other words, among all COPD patients, those with longer exposure to mineral dusts, organic dusts or exhaust fumes were less likely to have higher FeNO levels. It appears as though high and low FeNO levels are associated with different disease entities of lung disorders in individuals with long-term occupational exposure.

A study of spirometry-defined COPD that also used the NHANES 2007-2010 database ${ }^{11}$ found that the overall prevalence of COPD ranged from $10.2 \%$ to $20.9 \%$ based on whether pre-bronchodilator or post-bronchodilator values were used and applied to diagnosis. We found that COPD prevalence was $13.6 \%$ based on pre-bronchodilator results only, and this compares favorably to the previous study in which estimated prevalence was about $15 \%$ when defined by pre-bronchodilator results only. Unfortunately, the exposure of workers to many workplace hazards known to cause occupational COPD receives less attention than lifestyle risks such as smoking, alcohol use, and overconsumption of salt and sugar, ${ }^{10}$ which does not help promote reduction of workplace exposures. Workplace surveillance is often implemented within the internal occupational health services department of various industries and significant reductions in the number and severity of new cases of occupational asthma have been observed. ${ }^{17}$ However, surveillance is done in some industries only for satisfying regulatory requirements, which 
may serve mainly to identify and replace employees who develop occupational diseases,${ }^{10}$ rather than focusing on prevention. Blanc et a $1^{18}$ reported that the use of a single-item survey assessment of exposure to VGDF was able to delineate exposure risk as well as multiple-item battery assessment, and concluded that measuring exposure in the workplace effectively reduces risk when targeted to exposures in specific industries or occupations.

In the present study, exposure to mineral dusts, organic dusts, exhaust fumes and other fumes, and second-hand smoke was significantly associated with COPD prevalence, and subjects with longer term occupational exposure to these airborne pollutants had significantly higher risk for COPD compared to those who were not exposed. Self-reported exposure to VGDF occupational pollutants was formerly believed to overestimate risk of COPD and risk estimates may also have been influenced by cumulative exposure to several types of pollutants at different job sites or, for example, different biological dusts types. ${ }^{8}$ Nevertheless, causal associations between occupational exposure and COPD have been demonstrated consistently by multiple authors. ${ }^{9,14,19}$ Blanc and Torén ${ }^{20}$ found a causal association between work-related exposures and COPD with a population attributable risk percentage of $15 \%$. Rodríguez et $\mathrm{al}^{21}$ studied the effects of occupational exposure on characteristics of COPD, finding that exposure to dusts, gases and fumes was consistently associated with having higher COPD-related symptom scores and higher lung diffusion capacity, leading more typically to chronic bronchitis rather than to emphysema. However, based on spirometry variables, occupational exposure in that study was not associated with airway obstruction. This is an unexpected result since $\mathrm{FEV}_{1}$ is usually reduced in those with occupational exposure, and associations with COPD are usually demonstrated as well. ${ }^{14}$ In a study of COPD patients, those with VGDF exposure were older males who reported more work-related respiratory disability with asthma-like symptoms, and in both smokers and ex-smokers with COPD, occupational exposure was associated with distinct clinical characteristics, emphasizing possible interactions between genetic and environmental factors as well as risk factors. ${ }^{22}$

Results of the present study showed that individuals with lower FeNO levels tended to have greater risk for occupational exposure-related COPD than those with higher FeNO levels. Intermediate and long-term occupational exposure to inhalants appeared to reduce the clinical features of COPD, while the features of asthma emerged in subjects with $\mathrm{FeNO}>50 \mathrm{ppb}$, demonstrating eosinophilic airway inflammation. While longer exposure to occupational inhalation risks and FeNO $\leq 50$ ppb had a higher risk for COPD, the opposite was true in the group with $\mathrm{FeNO}>50 \mathrm{ppb}$, suggesting that airway inflammation caused by prolonged organic dusts and exhaust fumes exposure is less likely to be associated with asthmatic (or eosinophilic) lung conditions. These findings suggest that COPD patients with $\mathrm{FeNO} \leq 50 \mathrm{ppb}$ and longer exposure time may have COPD, while those with FeNO $>50 \mathrm{ppb}$ are more likely to have ACOS. The authors of several studies have suggested that VGDF exposure may contribute to either asthma or COPD, even though clinical features of both asthma and COPD may be present to some degree. ${ }^{23-25}$ Notable results of a cross-sectional populationbased study showed that occupational exposure to chemicals contributed significantly to the increased risk of asthma and rhinitis observed for VGDF exposure. ${ }^{25}$ Evidence is lacking, however, showing that VGDF exposure directly contributes to ACOS. Results of the present study do not indicate that ACOS patients are less susceptible to developing progressive airflow obstruction, or that eosinophils are a protective factor. Eosinophilic airway inflammation is associated with asthma and is increased in COPD exacerbations, and systemic corticosteroid treatment effectively mitigates such COPD exacerbation. ${ }^{26}$ However, it is not known whether controlling eosinophilic inflammation in COPD patients with airway eosinophilia is able to modify disease progression or alter mortality risk. ${ }^{26}$ Eosinophilic airway inflammation contributes to airway obstruction and symptoms in some COPD patients. ${ }^{27}$ Hospers et $a{ }^{28}$ showed that eosinophilia accompanied with asthma attacks is a risk factor for COPD mortality. High eosinophil counts were found in induced sputum of COPD patients, suggesting that eosinophils act as inflammatory cells not only in asthma but also in COPD. ${ }^{29}$ The evidence presented in these studies fails to demonstrate the protective effect of eosinophils and, conversely, indicates that eosinophilic inflammation is likely to cause severe symptoms in both asthma and COPD patients. Clearly, the role of eosinophils and eosinophilic airway inflammation in the pathogenesis of COPD, asthma and ACOS requires further study.

FeNO is a recognized marker for airway inflammation and is closely associated with bronchial eosinophilia; FeNO $>50$ ppb is also a marker for ACOS since degrees of airway inflammation can be differentiated. ${ }^{3}$ Studies have also reported increased NO in the exhaled breath of patients with asthma, which originates primarily from increased inducible nitric oxide synthase (iNOS) expression in the respiratory tract; in COPD, however, iNOS is not the primary source of $\mathrm{NO}$ and selective inhibitors of iNOS reduce FeNO levels in 
asthma but not necessarily in COPD. Results of Malerba et $\mathrm{al}^{3}$ suggest that, while iNOS is the main source of peripheral NO in asthma, neuronal nitric oxide synthase may be the primary source of NO in COPD.

Although FeNO is recommended as a clinical tool for the assessment of airway disease, considered to be an advance over pulmonary function testing alone for evaluating airway physiology, and its value in identifying airway inflammation is undisputed, ${ }^{30}$ some question may remain about the usefulness of FeNO in evaluating asthma severity ${ }^{31}$. Even with this capability, however, diagnosing ACOS may remain a challenge because the features of asthma and COPD may both be present. Our observation that FeNO levels in the two groups may suggest different disease entities may be in accord with the finding of Agustí et al ${ }^{32}$ that exhaled NO values in steroid-treated hospitalized patients returned to control levels after discharge, suggesting that different inflammatory mechanisms are present in COPD patients than those in highly responsive asthmatic patients. Of special note on the feasibility of FeNO measurement, Taylor et $\mathrm{al}^{30}$ advise that high FeNO levels ( $>50 \mathrm{ppb}$ ) can predict asthma relapse, while low FeNO levels ( $<20$ ppb in children and $<25$ ppb in adults) indicate asthma stability.

\section{Strengths and limitations}

The present study was strengthened by the use of populationbased NHANES data, which was collected from a nationally representative sample, allowing our results to be generalized to the entire US adult population. NHANES provided comprehensive information on subjects' demographics, socioeconomic status, smoking history and occupational exposures, helping to avoid biases in evaluating COPD risk. Several limitations are also noted including the use of cross-sectional analysis, which limits inferences regarding causality. Nevertheless, the retrospective survey included duration of occupational exposure, which helped to construct temporal relationships between exposure and outcomes. In addition, face-to-face interview data by questionnaire were self-reported and subjects may have recall problems or may have misunderstood questions, limiting the reliability of data. Results of this study cannot be generalized to populations other than the US population. Additional research is needed to corroborate our results in other populations and also to further investigate the roles of eosinophilic airway inflammation in the pathogenesis of COPD, asthma and ACOS.

\section{Conclusion}

Occupational exposure to airborne pollutants (mineral dusts, organic dusts, exhaust and other fumes, second-hand smoke) is significantly associated with COPD. Among individuals with long-term occupational exposure to dusts and fumes, those with lower FeNO levels ( $\leq 50 \mathrm{ppb}$ ) had higher risk for COPD than those without occupational exposure, and those with higher FeNO levels ( $>50 \mathrm{ppb}$ ) had substantially lower risk for COPD than non-exposed subjects, but may have had greater risk of asthmatic inflammation. Differences in FeNO levels ( $\leq 50 \mathrm{ppb}$ vs $>50 \mathrm{ppb}$ ) in subjects with long-term exposure to occupational inhalation risks suggest different disease entities for obstructive lung disorders. Results of the present study emphasize the importance of evaluating self-reported occupational exposure to dusts and fumes regardless of origins or duration of exposure, and also support the use of FeNO measurement in clinical practice, especially in diagnosis and management of asthma and ACOS, and also possibly to help distinguish them from COPD.

\section{Acknowledgments}

The authors wish to thank the NCHS for creating and releasing the NHANES data to clinical researchers. We acknowledge that the interpretation and reporting of these data are the sole responsibility of the authors.

This study was supported by a grant from the Taipei Tzu Chi Hospital, Buddhist Tzu Chi Medical Foundation (TCRD-TPE-106-RT-1).

\section{Author contributions}

Yi-Chih Huang: conception and design; acquisition of data; drafting of the manuscript; final approval of the manuscript; statistical analysis; literature research; obtaining funding.

Mei-Chen Yang: conception and design; analysis and interpretation of data; critical revision of the manuscript; final approval of the manuscript; guarantor of integrity of the entire study; definition of intellectual content; administrative, technical or material support; supervision.

\section{Disclosure}

The authors report no conflicts of interest in this work.

\section{References}

1. Eisner MD, Anthonisen N, Coultas D, et al; Committee on Nonsmoking COPD, Environmental and Occupational Health Assembly. An official American Thoracic Society public policy statement: novel risk factors and the global burden of chronic obstructive pulmonary disease. Am J Respir Crit Care Med. 2010;182(5):693-718.

2. Fabbri LM, Hurd SS; GOLD Scientific Committee. Global strategy for the diagnosis, management and prevention of COPD: 2003 update. Eur Respir J. 2003;22(1):1-2.

3. Malerba M, Radaeli A, Olivini A, et al. Exhaled nitric oxide as a biomarker in COPD and related comorbidities. Biomed Res Int. 2014; 2014:271918.

4. Fabbri LM, Rabe KF. From COPD to chronic systemic inflammatory syndrome? Lancet. 2007;370(9589):797-799. 
5. Tho NV, Park HY, Nakano Y. Asthma-COPD overlap syndrome (ACOS): a diagnostic challenge. Respirology. 2016;21(3):410-418.

6. Centers for Disease Control and Prevention (CDC). Chronic obstructive pulmonary disease among adults - United States, 2011. MMWR Morb Mortal Wkly Rep. 2012;61(46):938-943.

7. Salvi S. Tobacco smoking and environmental risk factors for chronic obstructive pulmonary disease. Clin Chest Med. 2014;35(1):17-27.

8. Sadhra S, Kurmi OP, Sadhra SS, Lam KB, Ayres JG. Occupational COPD and job exposure matrices: a systematic review and metaanalysis. Int J Chron Obstruct Pulmon Dis. 2017;12:725-734.

9. Omland O, Würtz ET, Aasen TB, et al. Occupational chronic obstructive pulmonary disease: a systematic literature review. Scand $J$ Work Environ Health. 2014;40(1):19-35.

10. Cullinan P, Muñoz X, Suojalehto H, et al. Occupational lung diseases: from old and novel exposures to effective preventive strategies. Lancet Respir Med. 2017;5(5):445-455.

11. Tilert T, Dillon C, Paulose-Ram R, Hnizdo E, Doney B. Estimating the U.S. prevalence of chronic obstructive pulmonary disease using pre- and post-bronchodilator spirometry: the National Health and Nutrition Examination Survey (NHANES) 2007-2010. Respir Res. 2013;14:103

12. Price D, Ryan D, Burden A, et al. Using fractional exhaled nitric oxide (FeNO) to diagnose steroid-responsive disease and guide asthma management in routine care. Clin Transl Allergy. 2013;3(1):37.

13. Dweik RA, Boggs PB, Erzurum SC, et al; American Thoracic Society Committee on Interpretation of Exhaled Nitric Oxide Levels (FENO) for Clinical Applications. An official ATS clinical practice guideline: interpretation of exhaled nitric oxide levels (FENO) for clinical applications. Am J Respir Crit Care Med. 2011;184(5):602-615.

14. Mehta AJ, Miedinger D, Keidel D, et al; SAPALDIA Team. Occupational exposure to dusts, gases, and fumes and incidence of chronic obstructive pulmonary disease in the Swiss Cohort study on Air Pollution and Lung and Heart Diseases in Adults. Am J Respir Crit Care Med. 2012;185(12):1292-1300.

15. Centers for Disease Control and Prevention (CDC). National Center for Health Statistics (NCHS). National Health and Nutrition Examination Survey Data 2007-2008, 2009-2010. Public Data General Release, U.S. Department of Health and Human Services, Centers for Disease Control and Prevention. Available from: http://www.cdc.gov/nchs/ nhanes/. Accessed June 22, 2017.

16. National Health and Nutrition Examination Survey (NHANES) Laboratory Data Protocol. U.S. Department of Health and Human Services, Centers for Disease Control and Prevention. Available from: https://wwwn.cdc.gov/nchs/nhanes/continuousnhanes/default. aspx?BeginYear=2007. Accessed June 22, 2017.

17. Tarlo SM, Liss GM, Yeung KS. Changes in rates and severity of compensation claims for asthma due to diisocyanates: a possible effect of medical surveillance measures. Occup Environ Med. 2002;59(1):58-62.

18. Blanc PD, Eisner MD, Balmes JR, Trupin L, Yelin EH, Katz PP. Exposure to vapors, gas, dust, or fumes: assessment by a single survey item compared to a detailed exposure battery and a job exposure matrix. Am J Ind Med. 2005;48(2):110-117.
19. Cullinan P. Occupation and chronic obstructive pulmonary disease (COPD). Br Med Bull. 2012;104:143-161.

20. Blanc PD, Torén K. Occupation in chronic obstructive pulmonary disease and chronic bronchitis: an update. Int J Tuberc Lung Dis. 2007; 11(3):251-257.

21. Rodríguez E, Ferrer J, Zock JP, et al; PAC-COPD Study Group. Lifetime occupational exposure to dusts, gases and fumes is associated with bronchitis symptoms and higher diffusion capacity in COPD patients. PLoS One. 2014;9(2):e88426.

22. Caillaud D, Lemoigne F, Carré P, et al; initiative BPCO Scientific Committee. Association between occupational exposure and the clinical characteristics of COPD. BMC Public Health. 2012;12:302.

23. Young MT, Sandler DP, DeRoo LA, Vedal S, Kaufman JD, London SJ. Ambient air pollution exposure and incident adult asthma in a nationwide cohort of U.S. women. Am J Respir Crit Care Med. 2014;190(8): 914-921.

24. Alif SM, Dharmage SC, Benke G, et al. Lifetime occupational exposure to vapor, gases/fumes, dust and risk of COPD at 45 years: the Tasmanian Longitudinal Health Study (TAHS). Am J Respir Crit Care Med. 2016;193:A2989.

25. Schyllert C, Rönmark E, Andersson M, et al. Occupational exposure to chemicals drives the increased risk of asthma and rhinitis observed for exposure to vapours, gas, dust and fumes: a cross-sectional populationbased study. Occup Environ Med. 2016;73(10):663-669.

26. Saha S, Brightling CE. Eosinophilic airway inflammation in COPD Int J Chron Obstruct Pulmon Dis. 2006;1(1):39-47.

27. Brightling CE, Monteiro W, Ward R, et al. Sputum eosinophilia and shortterm response to prednisolone in chronic obstructive pulmonary disease: a randomised controlled trial. Lancet. 2000;356(9240):1480-1485.

28. Hospers JJ, Schouten JP, Weiss ST, Rijcken B, Postma DS. Asthma attacks with eosinophilia predict mortality from chronic obstructive pulmonary disease in a general population sample. Am J Respir Crit Care Med. 1999;160(6):1869-1874.

29. Gorska K, Krenke R, Korczynski J, Domagala-Kulawik J, Chazan R. Eosinophilic airway inflammation in chronic obstructive pulmonary disease and asthma. J Physiol Pharmacol. 2008;59(Suppl 6):261-270.

30. Taylor DR, Pijnenburg MW, Smith AD, De Jongste JC. Exhaled nitric oxide measurements: clinical application and interpretation. Thorax. 2006;61(9):817-827.

31. Neelamegan R, Saka V, Tamilarasu K, Rajaram M, Selvarajan S, Chandrasekaran A. Clinical utility of fractional exhaled nitric oxide (FeNO) as a biomarker to predict severity of disease in response to inhaled corticosteroid (ICS) in asthma patients. J Clin Diagn Res. 2016; 10(12):FC01-FC06.

32. Agustí AG, Villaverde JM, Togores B, Bosch M. Serial measurements of exhaled nitric oxide during exacerbations of chronic obstructive pulmonary disease. Euro Respir J. 1999;14(3):523-528.
International Journal of COPD

\section{Publish your work in this journal}

The International Journal of COPD is an international, peer-reviewed journal of therapeutics and pharmacology focusing on concise rapid reporting of clinical studies and reviews in COPD. Special focus is given to the pathophysiological processes underlying the disease, intervention programs, patient focused education, and self management protocols.

\section{Dovepress}

This journal is indexed on PubMed Central, MedLine and CAS. The manuscript management system is completely online and includes a very quick and fair peer-review system, which is all easy to use. Visit http://www.dovepress.com/testimonials.php to read real quotes from published authors. 